\title{
Development of Electronic Funds Transfer Systems
}

\author{
WILLIAM C. NIBLACK
}

\begin{abstract}
Faster than any but the most optimistic thought possible, electronic banking is sweeping the country - overwhelming the laws that govern banks and other financial institutions, changing dramatically the banking and savings habits of millions of Americans. Ultimately, electronic banking will revolutionize the very concept of money itself and will probably force a profound change in how the Federal Reserve regulates the nation's money supply. Certainly it will touch off a flurry of competition for the nation's financial business unlike anything seen before. ${ }^{1}$
\end{abstract}

Developments in electronic funds transfer systems (EFTS) have long been a popular topic of discussion in banking circles, but as the above quotation from. a national business magazine indicates, the subject now enjoys even wider currency. Although it does not appear likely that we are on the threshold of "the checkless-cashless society," recent developments have been so rapid that predictions of future developments and effects of EFTS often seem foolhardy at best.

The diversity of views on the subject of EFTS reflects the broad scope of current developments. Many bankers see EFTS as providing an opportunity for initiating new services and reducing costs, thus increasing profitability. Others, especially those representing small banks, view EFTS as being prohibitively costly; they fear that they would not be able to compete with the larger banks which could afford the necessary computer equipment and, as a result, would be forced out of the market. Thrift institutions view EFTS as a means of obtaining deposits for which only commercial banks have heretofore been permitted to compete and have thus been in the forefront of EFTS developments.

Government will probably play a large role in the evolution of EFTS. Court interpretations of existing laws have already shaped the direction of some EFTS developments. New legislation and regulations will

I"Bank Cards Take Over the Country," Business Week (August 4, 1975), p. 44. almost certainly be adopted, but as yet no clear trend in the nature of these changes is discernible. Some of these changes may be dependent on the findings of the National Commission on Electronic Funds Transfers. This commission, which held its first meeting last February, is due to submit an interim report to Congress in October. It expects to complete its study and make recommendations by the end of $1977 .^{2}$

\section{ETTS AND THE PAYMENTS MECHANISM}

To speak of the electronic funds transfer system is an oversimplification. In fact, EFT developments are proceeding in several directions, with a number of different systems in various phases of development or use. The common factor in these systems is that they speed the transfer of funds by communicating information relating to payments by electronic means rather than by use of paper instruments as is predominant today. Thus, EFT systems are designed to replace manual processes with electronic data processing and to speed the flow of funds through high speed data transmission.

Although EFTS is often considered a revolutionary development with far-reaching effects, EFT developments can be viewed as just another step in the evolution of the payments mechanism - the system by which resources are transferred from one economic unit to another. This evolution reflects the continuing effort to improve the efficiency of trading. Money, which is simply a device which facilitates trade, represented an improvement over barter in that it reduced transactions costs and thus freed resources for use in the production of other goods and services. Checks came into widespread usage because they offered con" siderable advantages over cash; they were easily trans-

2"EFT Commission Rebufts Mitchell's Plea for Comment on Proposed Changes to Reg. J," American Banker (March 15, 1976), p. 1 . 
ported in any amount, easily transferred between individuals, involved much less danger of loss or theft than cash, and served as proof of payment. Checks thus reduced the transactions costs involved in making many types of money payments. Still, considerable transaction costs are associated with the processing of these paper documents.

Furthermore, because of the indirect nature of the check clearing process, there is often a delay in the availability of "good funds" for the payee. These delays can be costly, especially when large sums are involved. The development of wire transfers, through which banks can effect funds transfers by sending electronic messages rather than paper documents, represented a major improvement in the payments mechanism. One of the large wire transfer networks is operated by the Federal Reserve System, which transfers large volumes of funds for member banks and their customers through its computerized communications system. The dollar volume of funds transferred by the Federal Reserve Communications System in 1975 was almost seven times as large as the amount handled by the Fed's check clearing system." The average transfer is quite large - about $\$ 1.8$ million in 1975 - but the number of wire transfers is only a small fraction of the number of checks handled.

To the extent that wire transfers reduce transaction costs and processing time they can be said to improve the efficiency of the payments mechanism. However, the use of wire transfers has not significantly reduced the vast flow of paper through the payments system. A major reduction in paper volume would require implementation of electronic systems designed to be utilized for smaller retail-oriented payments, such as the systems described below.

\section{DESCRIPTION OF SOME EFT SYSTEMS}

For the sake of clarity and simplicity, EFT systems can be grouped into three categories: teller machines, point-of-sale systems, and automated clearing houses. These systems differ in types of payments handled and in means of processing.

\section{Teller Machines}

Machines through which an individual may conduct various routine banking services can be grouped under the heading of teller machines. Much of the recent EFTS development has involved these machines, which are called customer-bank communica-

BAnual Report of the Board of Governors of the Federal Reserve System (1975), p. 379. tion terminals (CBCTs) by the Comptroller of the Currency and remote service units (RSUs) by the Federal Home Loan Bank Board. In prineiple, these machines can be located either on a bank's premises or elsewhere, conceivably at great distances from the bank. They may be manned or automatic and vary greatly in complexity, ranging from simple communications terminals to more complicated automated teller machines (ATMs). Services which ATMs can typically perform include receiving deposits, dispensing funds from checking or savings accounts, transferring funds between accounts, making credit card advances, and receiving payments. The less complicated manned terminals handle the communications between the customer and his bank while the receipt or disbursing of funds is physically accomplished by the clerk who operates the terminal.

Teller machines are usually accessed by a combination of a magnetic stripe card (on which account information is encoded) and a personal identification number which, for security reasons, is known only to the customer. If the device is connected "on-line" to the bank's computer, the customer's account is updated immediately; otherwise, a record maintained in the machine is periodically delivered to the bank for processing.

\section{Point-of-Sale Systems}

On-line systems which allow customers to transfer funds to merchants in order to make purchases are usually called point-of-sale (POS) systems. Systems of this type may be used for check authorizations and credit card transactions, as well as for so-called "debit card" transactions in which funds are immediately transferred from the purchaser's account to the merchant's account. Conceivably, they could also be used for instantaneously transferring funds between businesses and/or individuals, using terminals or pushbutton telephones.

Large-scale POS systems generally operate in the following manner. On-line terminals are located at check-out counters or other points of sale. When making a purchase, a customer's card is inserted into a terminal which "reads" the data encoded on it. Other data concerning the transaction are entered manually by the clerk or through an electronic cash register or products code reader. If the customer's bank is different from the store's bank, a switching and processing center (SPC) connects the computers of the two banks. The computer at the customer's bank verifies that the card and identification code are valid and that the customer's account has sufficient funds. The 
customer's account is debited for the amount of the purchase while the store's account is credited for the same amount. Both parties to the transaction receive a printed statement at the time of the transaction, and the customer's regular bank statement contains a descriptive listing, much like those which many credit cards presently use. Since some 30 percent of personal checks are written to grocery or other retail stores, ${ }^{4}$ this type of system would allow automation of a substantial portion of check payments as well as many payments presently made by cash or credit card.

\section{Atrtomated Clearing Houses}

Another type of EFT system, which is conceptually different from the two systems described above, is the automated clearing house ( $\mathrm{ACH}$ ). As the name suggests, an ACH is analogous to a traditional clearing house, in that it represents a system for the interbank clearing of debits and credits. The main difference between automated and conventional clearing houses is that the debit and credit items in an ACH exist in the form of electronic signals, whereas they are paper items in a conventional clearinghouse operation. An $\mathrm{ACH}$ is thus not a system for automating the handling and clearing of paper checks. The payment items must enter the system in the form of electronic data, ustally computer-generated magnetic tape.

To illustrate how an ACH works, consider how a payroll payment could be made directly to an $\mathrm{em}$ ployee's checking or savings account through an ACH. The employee authorizes his employer to make such direct payments, eliminating the need for a check to pass through the employee's hands, be endorsed, cashed or deposited, and sent through the check clearing process to the employer's bank. The employer prepares the payroll data on computer tape and sends it to the company's bank. The bank directly credits the employee's account if he is a customer and combines the data for the remaining payees with those from other employers on a magnetic tape. This consolidated tape is delivered or transmitted to the $\mathrm{ACH}$, where a computer processes all the data for a day in a single run, sorting out all payees for each participating bank. Each bank then receives a computer tape (or paper advice if it is not equipped to handle tape) which lists the payees and the amount to be credited to each account. The employer's accounts are debited by the originating banks. Net settlement among the

\footnotetext{
tThis estimate is based on surveys reported in Research on Improvements of the Payments Mechanism: The Final Report on Phase I, An Analysis of Payments Transactions and Phase II, Payments Flow Data, Volume 1 of 3 (Atlanta: Georgia Teeh Research Institute, 1971), p. 30.
}

banks is accomplished in the same manner as with paper checks.

ACHs are especially suited for handling recurring payments, such as payroll, social security, or pension payments, or recurring payments made by individuals. Payors would authorize their banks to pay a specified amount to a payee (mortgage lender, insurance company, etc.) on a specified date. Parties to these types of payments would receive a descriptive statement documenting the payment.

Many types of payments - those where the payee and amount vary - are not amenable to this type of preauthorization. The case of regularly recurring bills of varying amounts, such as utility bills, represents a middle ground between the extremes of identical recurring payments and more or less random payments. The customer could, for example, authorize his bank to pay the amount billed by a specified creditor. ${ }^{5}$ Since many people are reluctant to give such broad power to their banks, a system called Bill Check has been developed. ${ }^{6}$ This type of payment allows the customer to control the amount and timing of payments to creditors but still achieves some of the benefits of ACHs.

An ACH thus differs considerably from teller machines and POS systems. The ACH is essentially a "batch" processing system used for the interbank settlement of recurring credits and debits, whereas many of the other systems allow instantaneous transfers of funds between the customer and his bank or from the customer to third parties.

\section{COSTS OF FUNDS TRANSTERS}

\section{Costs of the Check-Based Payments Sustem}

Knowledge of the number of checks written in a year and the cost of processing them is imprecise. However, it is estimated that in 1975 between 25 and

\footnotetext{
FAmerican Express has initiated such a service for credit card customers in California. Based on a preauthorization, the full amount of a credit card bill would be paid from the customer's bank accomt to American Express, unless the customer objected within a specified period after receiving the bill, See "American Express Will Begin Testing Preauthorized Payments through CACHA." Payment Systems News. letter (February 1975 ), p. 6.

The Bill Check itself is a portion of the bill on which the customer indicates the amount to be paid and signs his name, and then retums to the creditor. This completed form authorizes a debit from the customer's account to pay the bill. The creditor transfers the data to computer tape and sends the tape to the ACH for processing. The paper Bill Check is retained by the creditor for its records. See Atlanta Payments Project, Automated Clearing Houses; An In-Depth Analysis (Atlanta: Committee on Paperless Entries, 1974), pp. 35-39.
} 
30 billion checks were written ${ }^{\top}$ involving total processing costs of around $\$ 6$ billion. $^{8}$

When a payee cashes or deposits a check through a teller line, lock box, or other arrangement, the first bank receiving the check must encode the amount of the check in magnetic ink character recognition (MICR) readable symbols. This completes the encoding of the check (the bank's routing number and payor's account number are already encoded on the check), so most of the remaining processing can be conducted by machines capable of reading the MICR characters. The transit items (those drawn on other banks) are sent to the bank on which they are drawn, either directly or through a clearing house, correspondent bank, or the Federal Reserve's check collection facilities. When the check returns to the bank against which it is drawn, the writer's account is debited, and the cancelled check is returned to the writer with the periodic statement. Altogether, the average check is handled some ten times and passes through two and one-third banks."

Much of the processing described above is now automated. Machines read and sort the encoded check according to destination and perform most of the accounting functions. However, a number of the processing functions have not been amenable to automation. Many checks are still handled by tellers, the encoding process requires human handling, and the checks must still be physically transported through the banking system and back to the payor.

These manual processes appear to be among the most expensive in the check processing function. The average costs of these various processes were estimated by the Atlanta Payments Project through surveys of Atlanta banks. ${ }^{10}$ The estimated cost of receiving an item through a branch was $7.4 \%$ and the cost of proof and encoding an item was $1.3 \dot{\phi}$. Together, these accounted for nearly 60 percent of the

TAccorting to one estimate more than 24 billion checks were processed in 1974, with the number increasing at a 7.3 percent annual rate between 1971 and 1974. See $\mathrm{R}$. William Powers, "A Sturvey of Bank Cheok Volumes," Journal of Bank Research. (Winter 1976), pD. 245-56.

8 The latest estimates of average check processing costs of commercial banks are in the $16-2$ le range. To these costs must also be added the indirect costs bome by writers and receivers of checks, as well as Federal Reserve expenses for check clearing. See Arthur D. Little, Inc., The Conseguences of Electronic Funds Transfers, prepared for the National Science Foundation (1975), p. 51 .

"Mark J. Flannery and Dwight M. Jaffee, The Economic Implications of an Electronic Monetary Transfer System (Lexington, Mass: D.C. Heath and Company, 1973), p. 41.

10Atlanta Payments Project, Atitomated Clearing Houses: An In-Depth Analysis, pp. 218-19.
13.9 $\%$ cost of processing an "on-us" item (a check deposited in the bank on which it was drawn) and more than 80 percent of the $10.6 \%$ cost of a transit item. ${ }^{11}$

Given this situation, the prospects of lowering the average cost of check processing materially below its present levels do not appear to be good. Economies of scale in check processing may well be nearly exhausted. As labor and other costs rise, the average cost of check clearing is also likely to rise.

These factors have led many to believe that radical changes in the payments mechanism are necessary if costs are to be kept at present levels or be reduced. If the paper document which carries the payments data can be replaced by an electronic signal, manual handling can be significantly reduced and the flow of payments data accelerated by high speed data transmission.

\section{Cost Characteristics of ETTS}

Although few cost data are available because of the limited experience with EFTS, some dated but representative cost estimates are available. Most EFT systems involve large total cost, much of which is associated with the expensive computer hardware necessary to operate these systems: computers, terminals, and communication links. Even teller mam chines, which are among the less expensive types of systems, involve purchase costs that may exceed $\$ 40,000$ per ATM, depending on features.

More complicated systems involve higher total costs. An on-line POS system would involve high costs not only for the banks' computers, the terminals in stores, and the communications links joining them, but also for the SPC which interconnects the computers of the different banks. In one study, published four years ago, the Atlanta Payments Project estimated total costs for a proposed POS system linking the banks in that city.12 These included about $\$ 650,000$ for SPC processing equipment and $\$ 655,000$ for SPC development costs, about $\$ 1,200$ for each terminal and associated communications equipment, and about $\$ 54,000$ for bank communications interface equipment.

\footnotetext{
11An interesting sidelight of this study is that much of the cost of processing a check is borne by the bank of first deposit rather than the bank on which the check is drawn. Of course, the cashing bank frequently receives new deposits in the process which can compensate it for the costs it bears.

12Atlanta Payments Project, Research on Improvements of the Payments Mechanism: Phase $I I I$ General Systems Design and Analysis of An Electronic Funds Transfer System, Volume 3 of 6 Systems Design and Analysis-Point of Sale System (Atlanta: Georgia Tech Research Institute, 1972), Chapter 8.
} 


\section{COMPETITIVE QUESTIO}

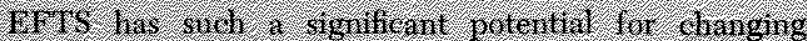

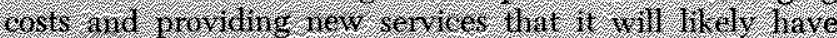

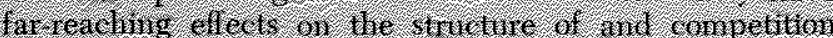

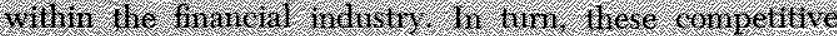

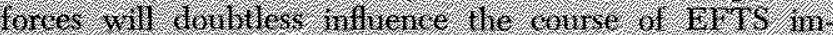

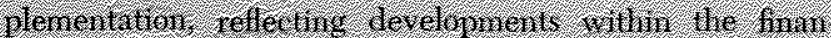

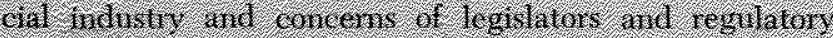
ageneies.

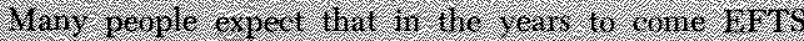

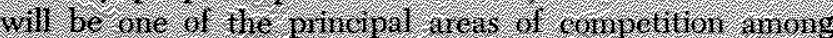

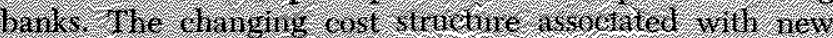

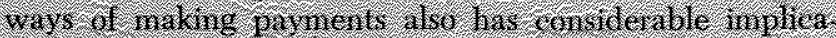

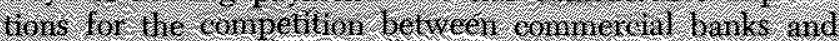
thind instivations:

\section{Competition and Regulation}

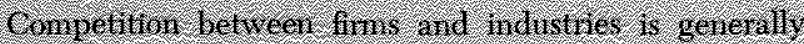

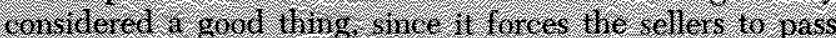

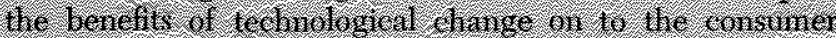

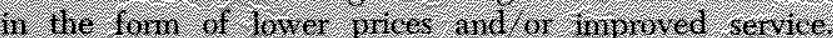

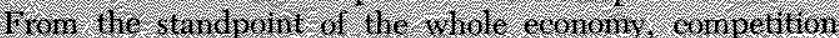

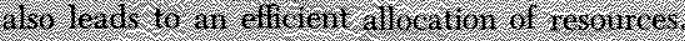

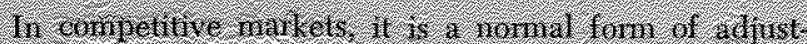

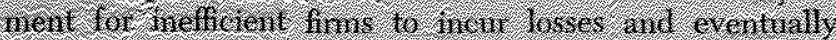

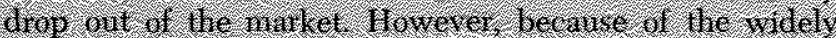

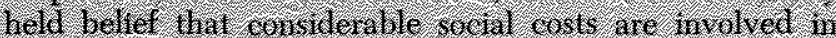

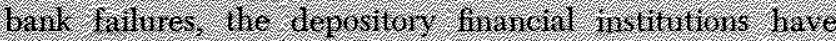

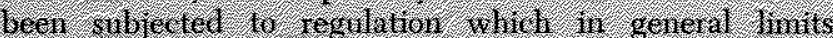

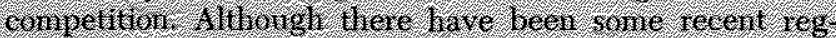

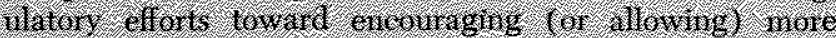

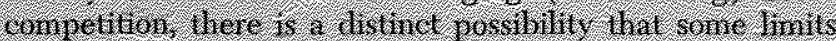

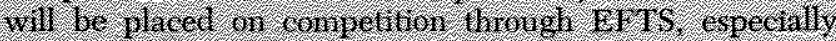

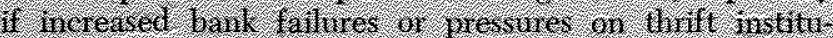

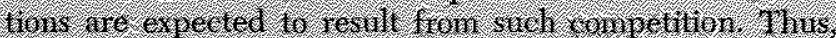

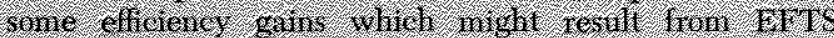

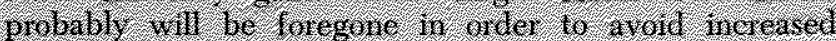
tillires.

\section{Effect on Structure}

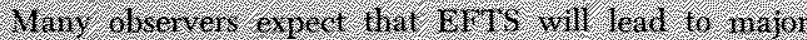

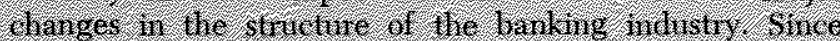

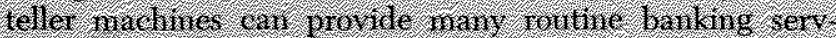

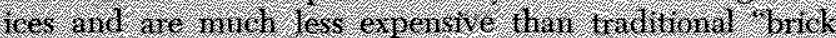

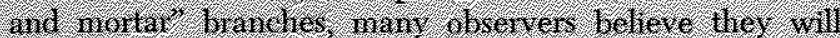

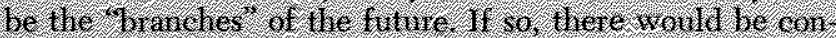

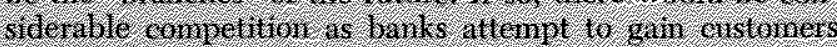

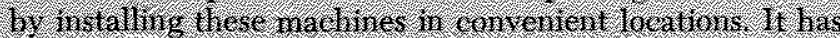

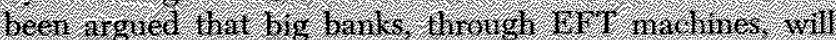

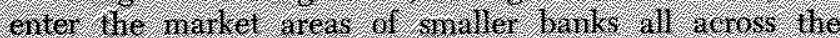

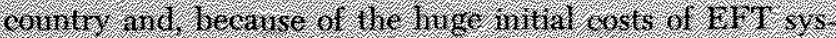

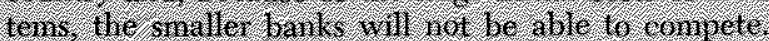

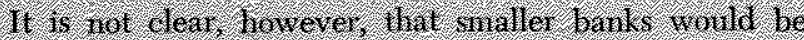

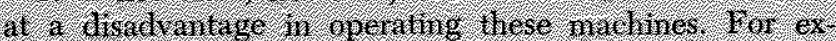

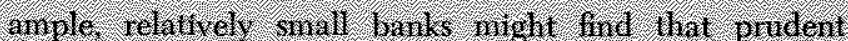

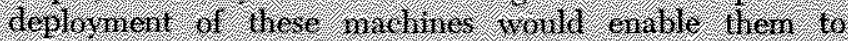

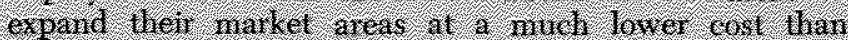

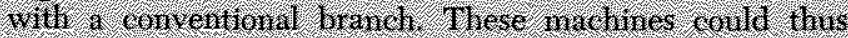

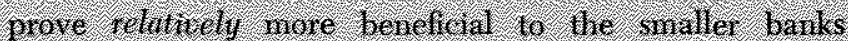

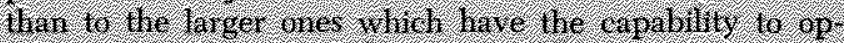
sare a lave nimber at cruventiond branches.

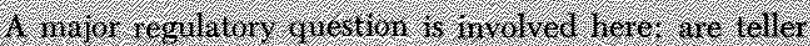

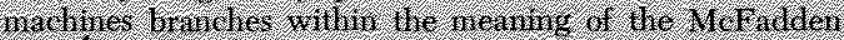

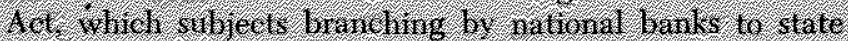

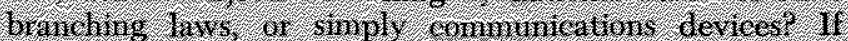

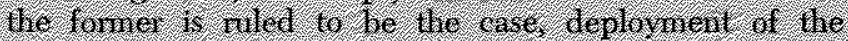

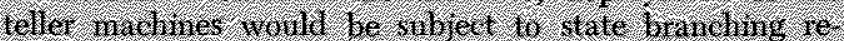

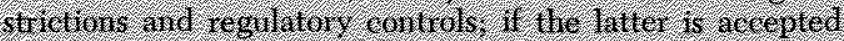

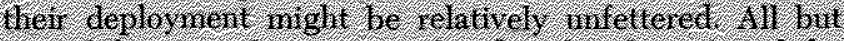

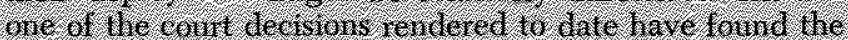

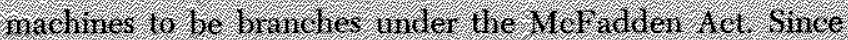

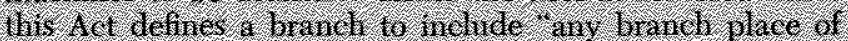

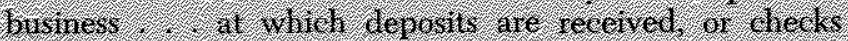

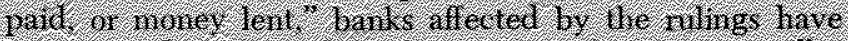

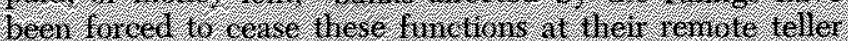

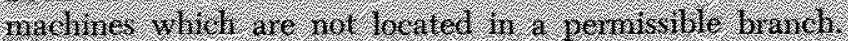

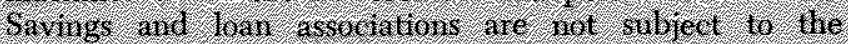

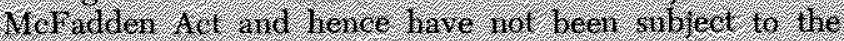

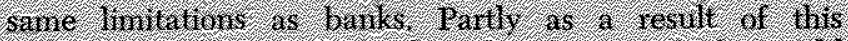

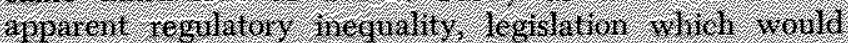

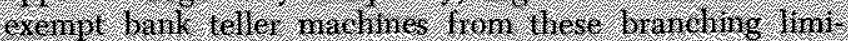

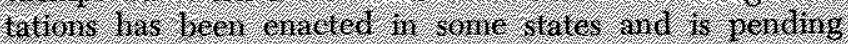
in $011 \mathrm{hr}$.

\section{Ownership of ETT Systems}

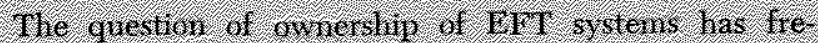

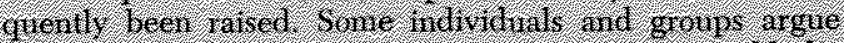

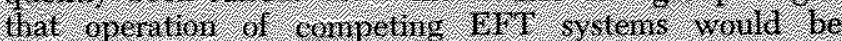

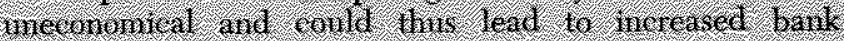

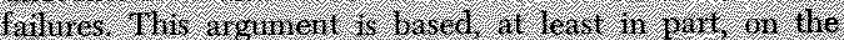

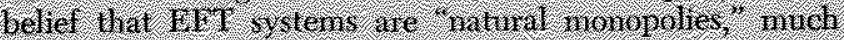

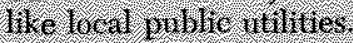

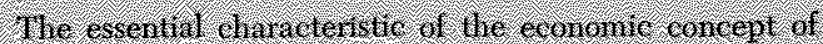

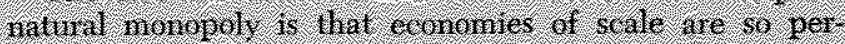
whive that average costs dectine over he enthe extent

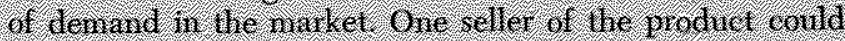

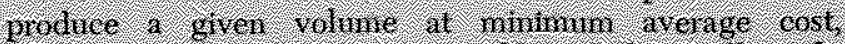

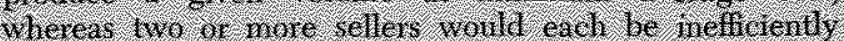

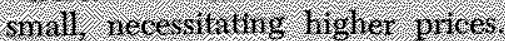

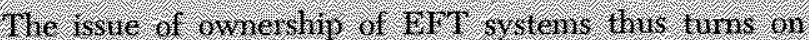

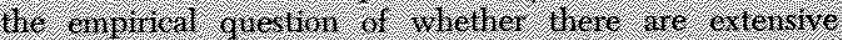

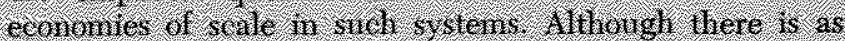

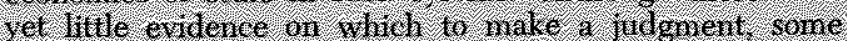

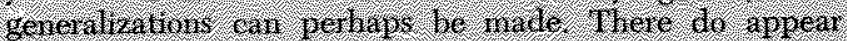

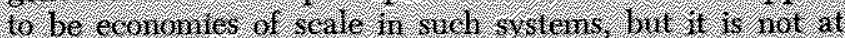

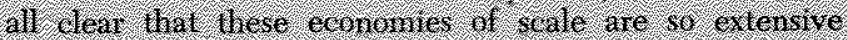

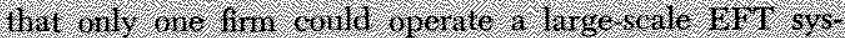

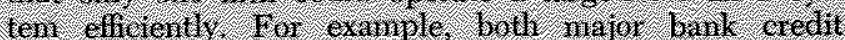




\section{IRROUNDING EFTS}

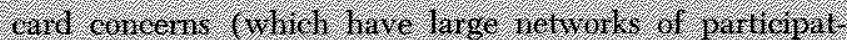

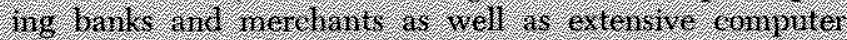

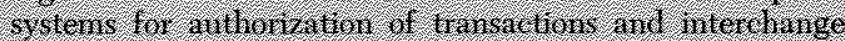

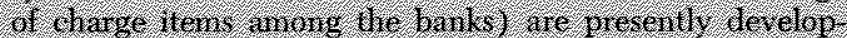

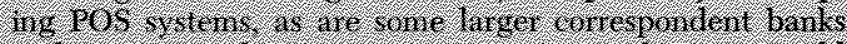

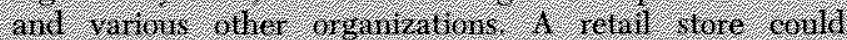

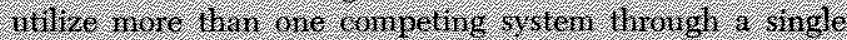

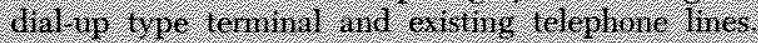

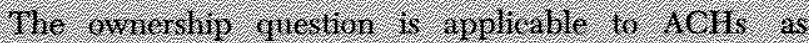

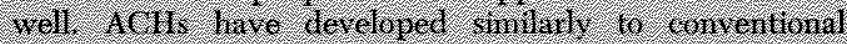

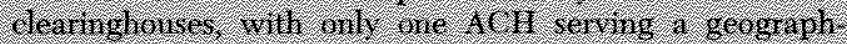

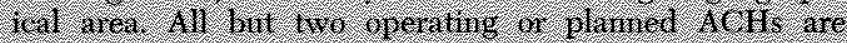

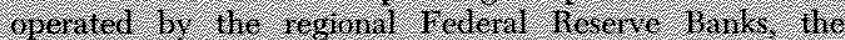

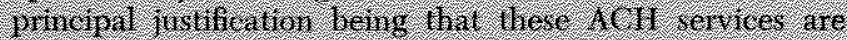

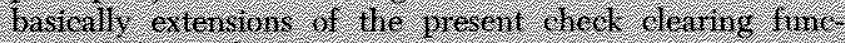
trait of llie 1 ed.

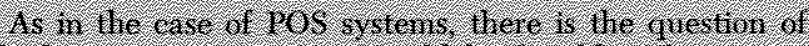

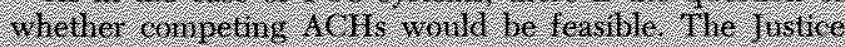

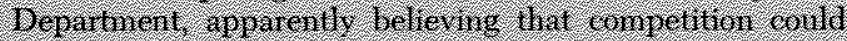

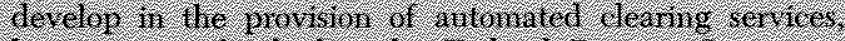

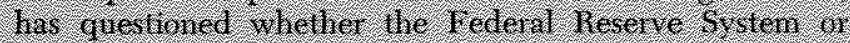

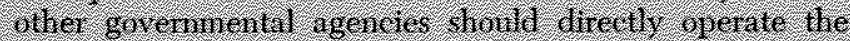
$4(1)$

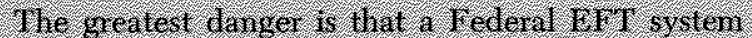

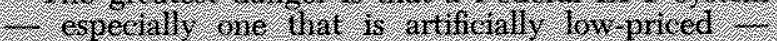

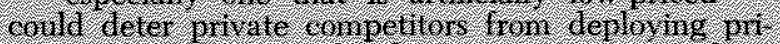

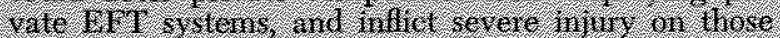

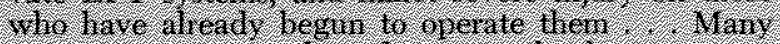

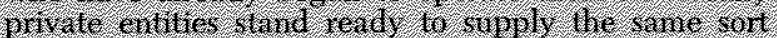

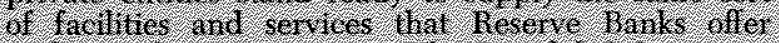

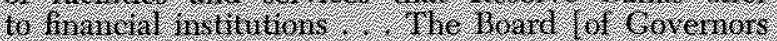

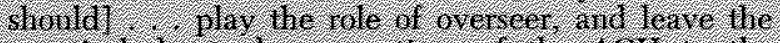

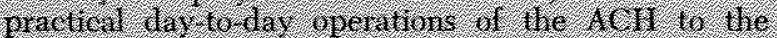

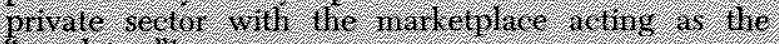
tregulation

\section{Nole of Thiff Institutions}

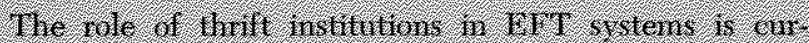

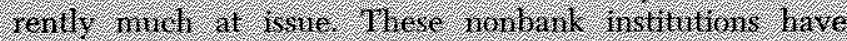

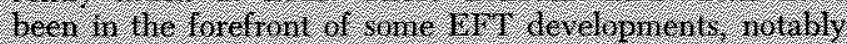

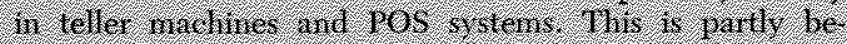

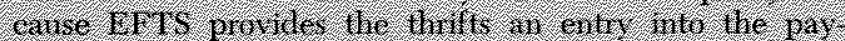

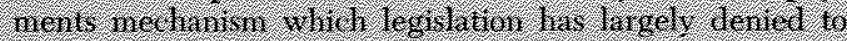

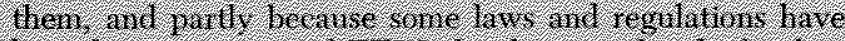
f $13.101,115$

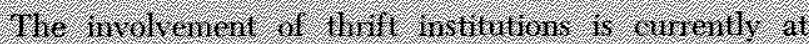

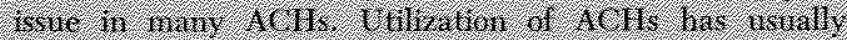

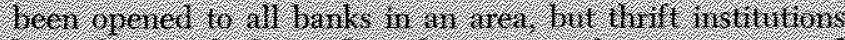

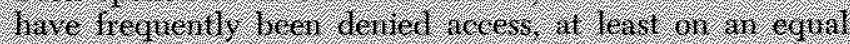

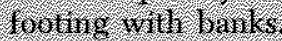

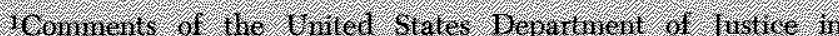

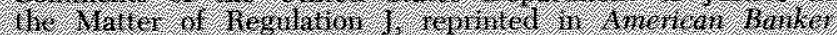

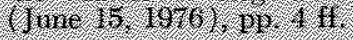

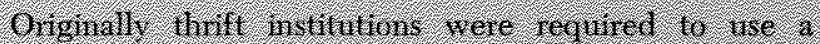

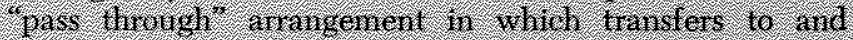

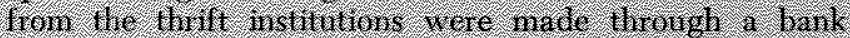

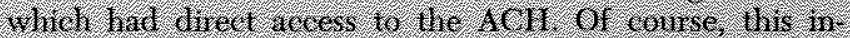

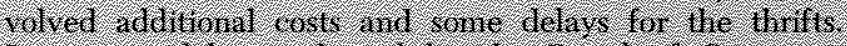

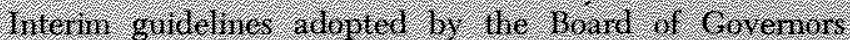

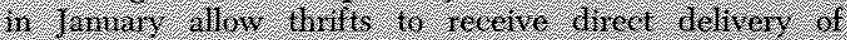

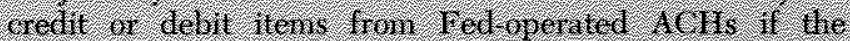

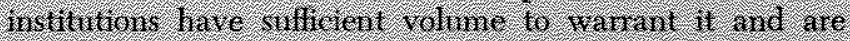

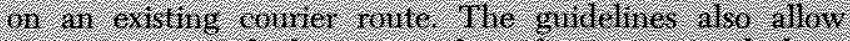

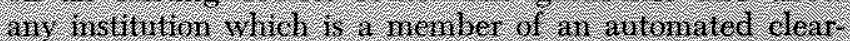

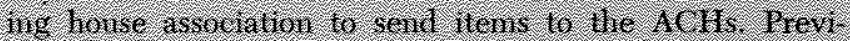

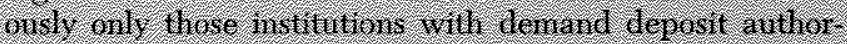

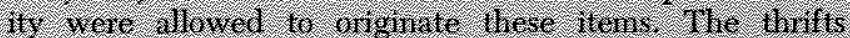

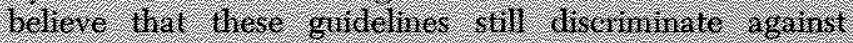

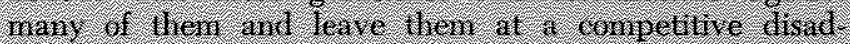

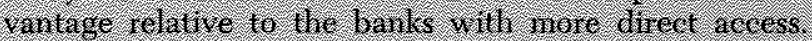

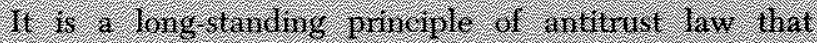

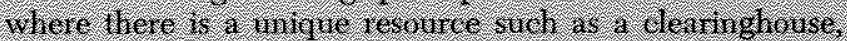

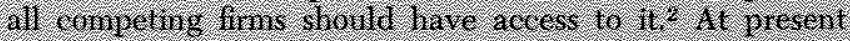

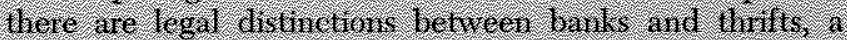

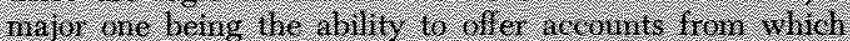

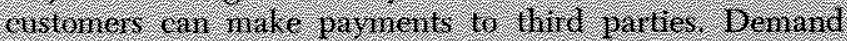

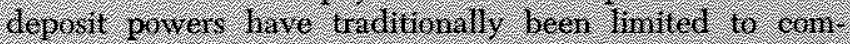

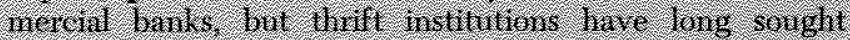

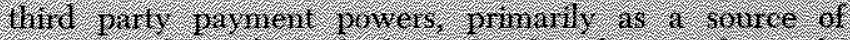

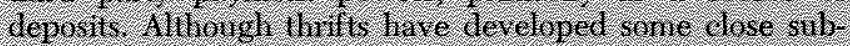

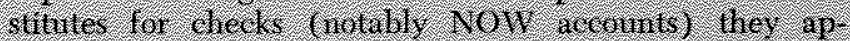

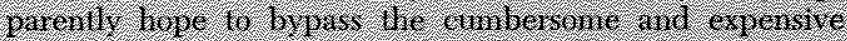

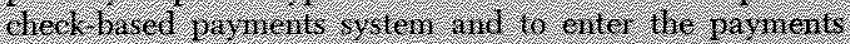

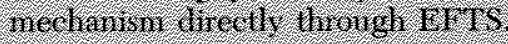

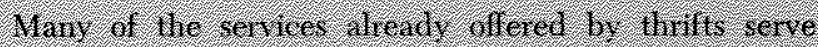

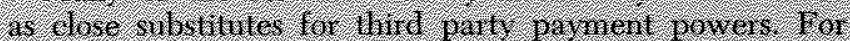

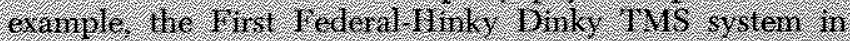

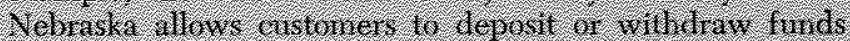

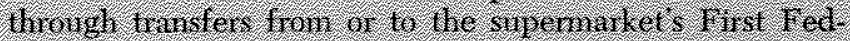

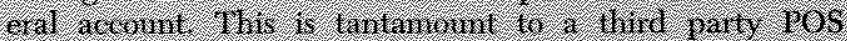

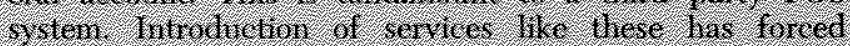

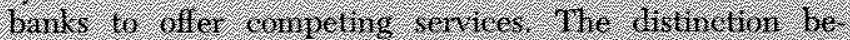

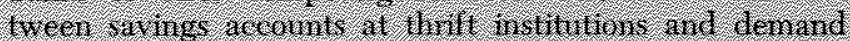

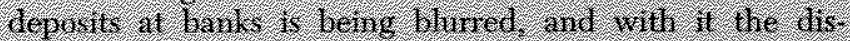

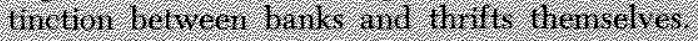

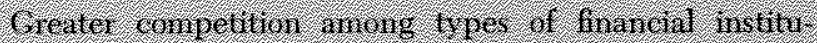

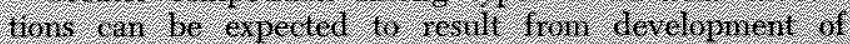

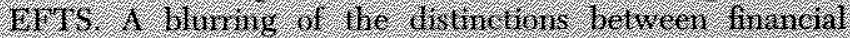

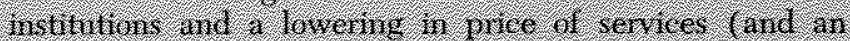

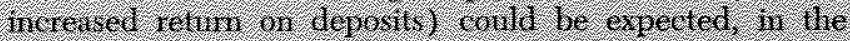

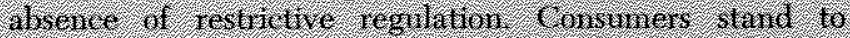

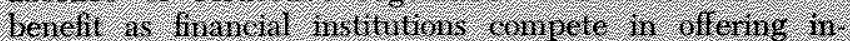

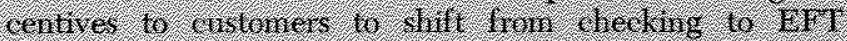

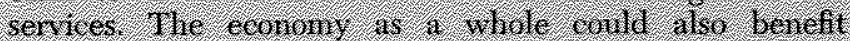

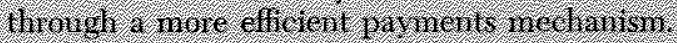

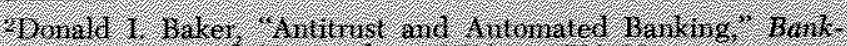

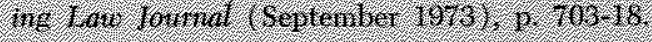


The Federal Reserve Bank of Cleveland has estimated total costs of operating a larger POS system, which would link 39 banks in the Fourth Federal Reserve District. ${ }^{13}$ Assuming that the system would capture 6.7 percent of total retail transactions, in the tenth year the average costs of operating the SPCs alone would be an estimated $\$ 3.8$ million. Costs of participating banks in the tenth year would be another $\$ 13.9$ million, it was estimated. Total costs for the first ten years of operation would exceed $\$ 100$ million.

Many of the costs which are associated with EFT systems do not vary with the number of transactions and thus can be considered as fixed costs. An example is the depreciation of the computers, terminals, and other equipment used in the system, which would be the same regardless of the level of usage. Some other costs probably do not vary significantly with the level of usage either. The costs of operating a computer used solely for an EFT system would probably be little higher at relatively high levels of transactions than at low.

There are other costs which do vary with the level of output or usage. For example, labor costs associated with operating a manned terminal may be greater at higher levels of usage than at low. The cost of computer time necessary to process teller machine or POS transactions would also depend on the number of transactions. One study estimated the cost of the infinitesimal amount of computer time necessary to process a POS transaction to be about li per transaction. ${ }^{14}$

To date, ACHs have utilized an existing computer (in most cases at a Federal Reserve Bank), since a computer run processing a whole day's accumulated items usually takes an hour or less. The processing time and labor costs do not appear to vary greatly with the number of transactions processed. Estimated costs of operating the Atlanta ACH at various levels of output are shown in Table $I$.

A characteristic of the costs of many EFT systems is evident in this table: the average cost of a transaction declines significantly as the number of transactions increases. This is caused by the predominance of relatively fixed costs in most EFT systems. From the standpoint of the Federal Reserve System, which operates most ACHs, a high level of output would

${ }^{13}$ Arthur D. Little, Inc., The Consequences of Electronic Funds Transfer, pp. 195-8.

14Atlanta Payments Project, Research on Improvements of the Payments Mechanism: Phase III, Vol. 3 of 6 , p. 166 .

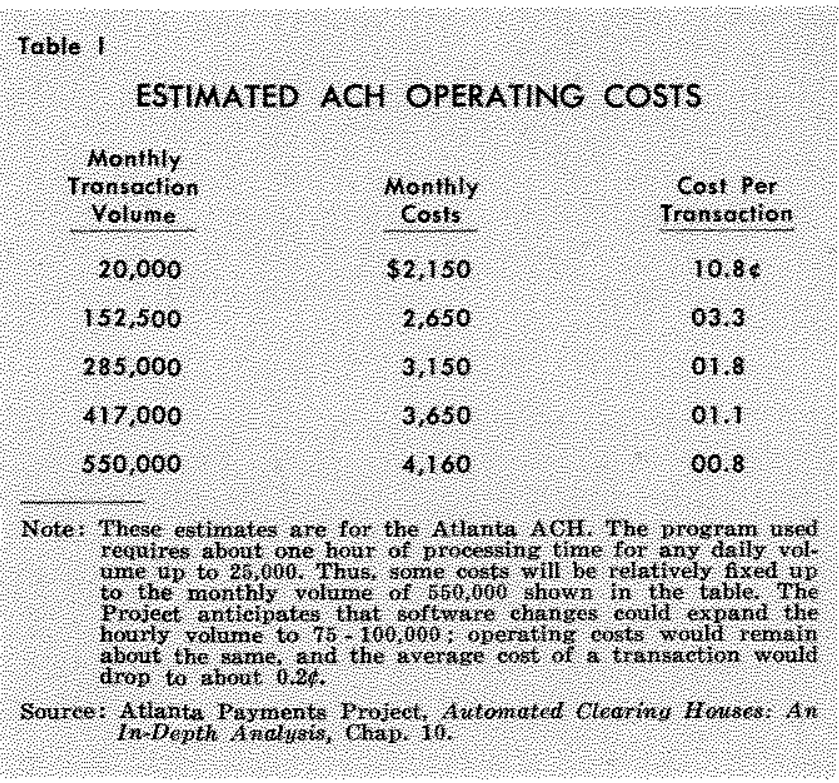

have to be reached before the average cost of a transaction would fall below the Fed's average cost of clearing a check, which is about $1 \phi$. The data on Federal Reserve check processing and ACH costs presented in Table II indicate that, at current volumes, processing an ACH item is much more expensive to the Fed than processing a check. Of course, this means that $\mathrm{ACHs}$ are presently operating at far less than efficient volumes. Furthermore, potential cost savings to participating banks from making electronic payments through an $\mathrm{ACH}$ rather than using checks should also be considered. Data from the Atlanta Payments Project suggest that monthly volumes of more than 160,000 transactions at the Atlanta ACH would result in the average cost of an ACH transaction falling below the average cost of a check. ${ }^{15}$

Estimates of average costs of POS transactions also suggest that if sufficiently large volume is attained, the average cost of a POS transaction can fall below the average cost of a check. In the Cleveland Fed study, referred to above, the average cost per transaction over a three-year period was estimated to be $11.3 \%$; this would be reduced to $7.1 \mathrm{e}$ by the tenth year because of expected economies of scale in operation of the system. ${ }^{16}$

\footnotetext{
${ }^{15}$ Atlanta Payments Project, Automated Clearing Houses: An In-Depth Analysis, p. 229. This estimate assumes no bank marketing costs associated with the ACH operation.

${ }^{16}$ Arthur D. Little, Inc, The Consequences of Electronic Funds Transfer, pp. 195-98. The Cleveland Fed Study estimates that the POS system would generate cost savings such that the annual savings wonld exceed ammul costs by the seventh year and cumulative savings exceed cumulative costs by the tenth year. This estimate did not include savings experienced by merchants as a result of using the POS system.
} 


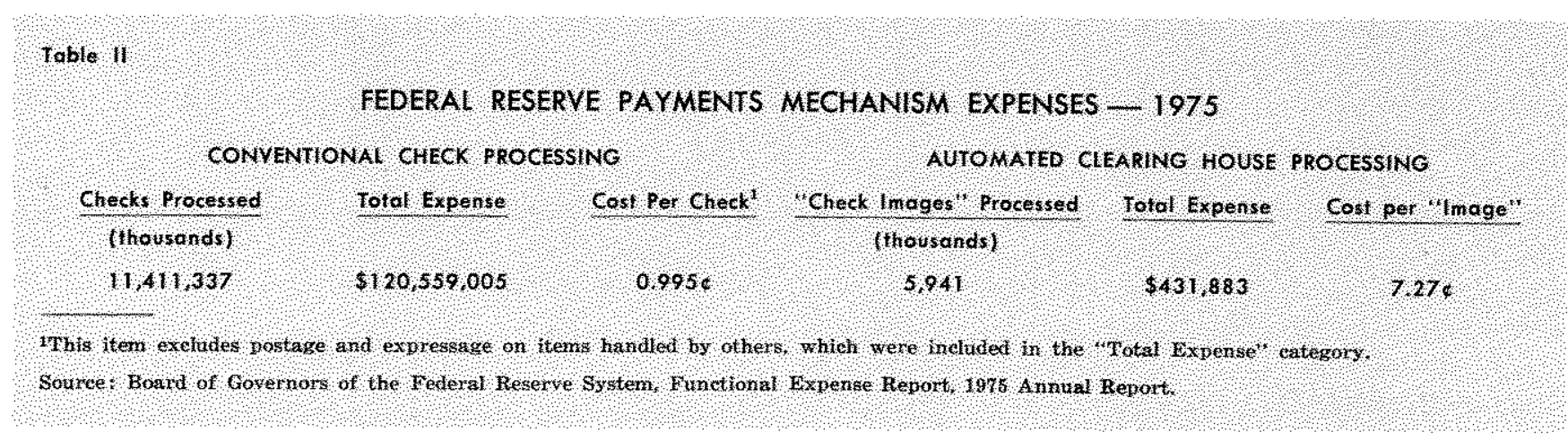

Another cost concept should be considered. This is marginal cost, which is simply the change in total cost which results from increasing output by one unit. Marginal cost is thus not affected by fixed cost but only by variable costs. In the case of EFT systems, the marginal cost would be the change in cost that resulted from conducting one additional transaction. The considerations described above suggest that the marginal cost of an EFT transaction is likely to be very low. In most cases, little or no additional labor is involved, and only an infinitessimal amount of computer time is used. Thus, an additional transaction should add very little to the cost of the system. In comparison, the marginal cost of a check is probably relatively high because of the labor intensiveness of check processing. ${ }^{17}$

In summary, many EFT systems will involve large fixed costs but relatively small variable costs. Because of this predominance of fixed costs, average costs of EFT transactions will probably decline over a fairly large range of output. The hypothetical cost curves

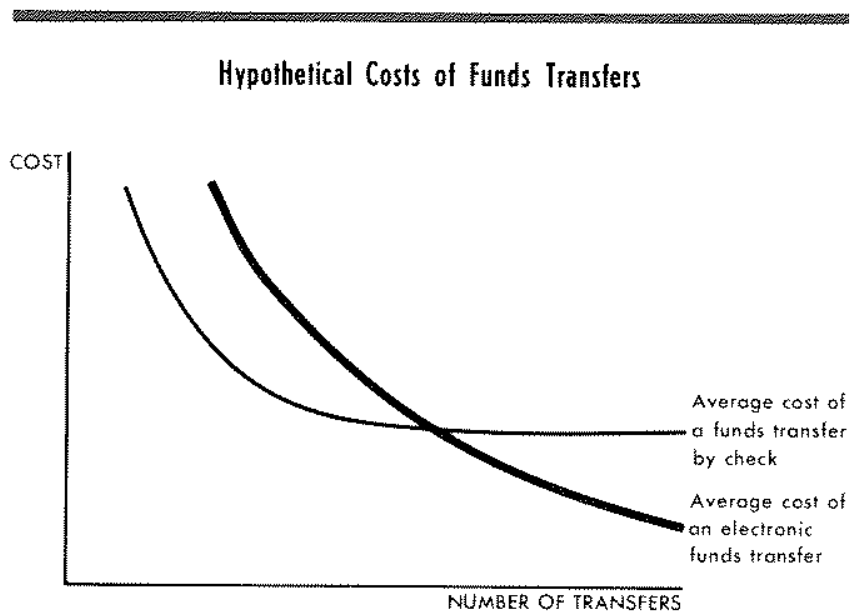

7One study estimated the marginal cost to be $14 \mathrm{c}$, not nuch below the average cost estimated in the same study. Flannery and Jaffee, The Economic Implications of an Electronic Monetary Transfer System, p. 42, footnote 10. presented in the accompanying figure show the average cost of an electronic funds transfer to be grenter than the average cost of a check at relatively low volumes. Beyond some point, however, the average cost of checks levels off while that of electronic funds transfers continues to fall. The average cost of electronic transfers is less than that of checks for relatively large volumes. Although these cost relationships are hypothetical, they demonstrate the general relationship between the costs of check systems and EFTS.

\section{CUSTOMER ACCEPTANCE OF ERTS}

If the potentially lower unit costs of EFTS are to be realized, a substantial proportion of present payments must be switched to electronic means. Otherwise, banks may find themselves with the worst of both worlds: a large, slow, expensive check handling system, plus a very expensive underutilized EFT network. Thus, failure to consider customer acceptance of EFTS could have exactly the opposite effects from those hoped for.

At present, there seems to be little incentive for customers to change their payments practices from using checks to EFT systems. Surveys have found that individuals are generally satisfied with the present payments system. Using checks provides many benefits, including unquestioned proof of payment. The surveys also indicate that many individuals, especially those in lower income groups, have a negative attitude toward many aspects of EFT systems. ${ }^{18}$ Customers tend to fear a "loss of control" over their finances which would result from preauthorized deposits or withdrawals, as well as possible losses of privacy, costly errors, and lack of proof of payment. Thus, in many cases, it may take considerable incentive to induce individuals to shift their payments from checks to electronic means.

${ }^{18}$ See Arthur D. Little, Ine, The Consequences of Electronic Ftunds Transfer, pp. $43-46,253-63$. 
Such an incentive could be provided if the cost savings which would result from a fully utilized EFT system were passed on to the customer. However, current regulations reduce the likelihood of banks providing such incentives. For example, since banks are prohibited by Regulation Q from paying an explicit return on demand deposits, they usually pay an implicit return by subsidizing the checking costs of their customers, either totally or in part. ${ }^{19}$ Thus, the cost to the individual of writing an additional check is usually less than the marginal cost to society of processing the check. As a result, "too many" checks are written, and a greater than optimal quantity of resources is allocated to check processing. As long as banks are prohibited from explicitly paying interest on demand deposits, it does not seem likely that they will charge fees for checking services which approximate the marginal costs of the checks. As a result, the prospects of banks providing sufficient incentives for customers to switch from checking to the lower-marginal-cost electronic funds transfer services are reduced.

19."Yields' on Checking Accounts Rise in Recent Years" Federal Reserve Bank of Philadelpha Business Review (March 1975), pp. 14-15.
The underutilization of EFT systems which would stem from the prohibition of interest on demand deposits could be worsened if customers receive additional disincentives to use EFT systems. Such disincentives could take the form of high initial prices for EFT services which banks may charge, predicated on the notion of recovering the large fixed costs of the EFT systems relatively quickly.

\section{SUMMARY}

Many of the questions surrounding EFTS cannot yet be answered definitely, since they depend on costs, regulations, and other factors for which there are few or no data. However, it is reasonable to expect marginal costs of making a transfer through EFTS to be less than through the check system; average costs of transfers could also be lower, if a sufficiently large volume is achieved. Such possibilities for reducing costs, other things equal, would encourage banks and other producers to increase their supply of these services relative to checking services. However, such factors as the prohibition against paying interest on demand deposits appears to reduce the incentive for customers to use EFT systems, thus slowing their development.

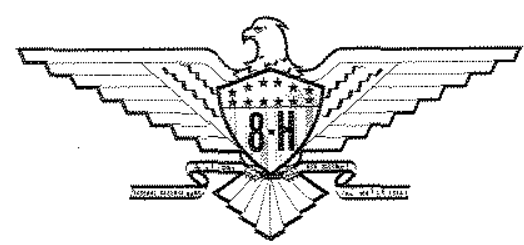

